\title{
Pyruvate Kinase Measurement
}

National Cancer Institute

\section{Source}

National Cancer Institute. Pyruvate Kinase Measurement. NCI Thesaurus. Code C156470.

The determination of the amount of pyruvate kinase present in a sample. 